\title{
'PRECOCE DE ITUPEVA' E 'BRANCA DE GUAPIARA' - NOVOS CULTIVARES IAC DE NECTARINA BRANCA (1)
}

\begin{abstract}
MARIO OJIMA. FERNANDO ANTONIO CAMPO DALLORTO (2). ANTONIO FERNANDO CAETANO TOMBOLATO, WILSON BARBOSA (3), Segão de Fruticultura de Clima Temperado, ORLANDO RIGITANO, Divisão de Horticultura, JAIRO LOPES DE CASTRO, Estacão Experimental de Capão Bonito, HẼLIO JOSÉ SCARANARI, FERNANDO PICARELLI MARTINS (2), Estạão Experimental de Jundiaí, e SEBASTIÃO ALVES, Estagāo Experimental de Monte Alegre do Sul, Instituto Agronómico.
\end{abstract}

\section{RESUMO}

'Precoce de Itupeva' (IAC N 4474-5) e 'Branca de Guapiara' (IAC N 2374-8) são dois novos cultivares de nectarina, obtidos no Instituto Agronômico de Campinas, dentro do seu programa de melhoramento genético. Trata-se de seleçōes obtidas na geração $\mathbf{F}:$, atravếs de cruzamentos originais entre cultivares locais de pêssego e os de nectarina procedentes da Flórida (EUA). Os frutos são de polpa branca, de caroço solto e de paladar doce-acidulado agradável, com doçura pronunciada. As plantas apresentam alta produtividade, demonstrando assim pequena exigência de frio, o que propicia novas opçōes para a escolha do material a ser cultivado nas condições de inverno ameno do Estado de São Paulo e nas regiôes de ecologia similar.

\section{INTRODUÇÃO}

A nectarina, que é explorada em São Paulo somente nos últimos doze anos, recebe incremento notável nas zonas persicolas do Estado, onde se calcula existirem atualmente cerca de 50.000 árvores plantadas comercialmente. Dois cultivares, até o momento, são os responsáveis

(1) Recebido para publicação a 20 de maio de 1983.

(2) Com bolsa de suplementação do CNPq.

(3) Com bolsa de aperfeiçoamento da FAPESP. 
pela difusão da nectarina no Estado, graças à boa adaptabilidade demonstrada nas nossas condições de inverno brando: 'Rubro-sol' ('Sunred') (4), o mais cultivado, e 'Colombina' (Fla 19-37 S), procedentes da Flórida (EUA), e introduzidos pelo IAC em 1969 (3). Esses dois cultivares se assemelham em precocidade de maturação, apresentam frutos atraentes, de pele avermelhada, polpa amarelo-clara, caroço solto, e sabor doce-acidulado apenas razoável.

Outras seleções introduzidas da Flórida - Fla 44-28 e Fla 15-85 $(3,5)$ - mais exigentes de frio, não mostraram adaptação satisfatória no planalto paulista; apenas têm-se revelado de interesse para fins de melhoramento e promissoras para o cultivo nas regiōes mais frias do Estado, a exemplo de Campos do Jordão e Itararé.

Até hoje, as tentativas feitas em São Paulo, para o cultivo de nectarinas introduzidas de outras procedências, fracassaram. Assim, tem-se verificado a necessidade de obtenção de novos cultivares, especialmente adaptados às nossas condições ambientes, de melhor palatabilidade que aqueles atualmente em cultivo, e abrangendo um período mais amplo de maturação. Com esse propósito, o Instituto Agronômico iniciou, em 1970 (2), o programa de melhoramento da nectarina, por meio de hibridaçóes, utilizando como progenitores básicos os pêssegos IAC (1) e as nectarinas introduzidas da Flórida. Dentre os vários tipos de nectarinas surgidos na geração $F_{2}$ desses cruzamentos, foi possivel eleger duas seleções de boas qualidades agronômicas, as quais são apresentadas como novos cultivares à exploração comercial.

\section{MATERIAL E Métodos}

Em julho de 1970, efetuou-se, no Centro Experimental de Campinas, uma série de cruzamentos controlados, utilizando-se, como progenitores femininos, 16 cultivares locais de pêssego, adaptados às nossas condições climáticas, e como masculinos, três de nectarina, procedentes da Flórida. Esses cruzamentos abrangeram 27 combinações, das quais apresentam interesse para o presente trabalho, as designadas por 2370 - 'Cristal' $\mathrm{x}$ 'Colombina' e 2670 - 'Supermel' $\mathbf{x}$ 'Colombina', e que, na geração $\mathbf{F}_{2}$, deram origem aos dois cultivares de nectarina aqui relatados, cujos progenitores sāo descritos a seguir:

'Cristal' (IAC 159-1) - Pêssego de polpa branca, caroço preso e sabor doce-acidulado, bem equilibrado. Originário do cruzamento 'Súber' $\mathbf{x}$ 'Pérola de Itaquera', é uma das seleções mais significativas de pêssego para mesa do IAC.

'Supermel' (IAC 2-87) - Pêssego branco, de caroço preso, sabor essencialmente doce, daí o seu nome. Provém da autofecundação de 'Néctar' (IAC 1453-1), que, por sua vez, descende do cruzamento 'Pérola de Itaquera' $x$ 'Jewel'. 'Trata-se de um pêssego que não teve penetração nas culturas comerciais, porém a sua característica de sabor doce-acentuado foi aproveitada no programa de melhoramento. 
'Colombina' (Fla 19-37 S) - Nectarina bem avermelhada, de polpa amarela e caroço solto; sabor agridoce marcante. Introduzida da Flórida (EUA), em 1969, é cultivada em pequena escala pelos fruticultores paulistas. Provém da polinização livre da nectarina Fla 44-28, que, por sua vez, tem a origem: ('Okinawa' x 'Panamint') x NJN 21.

Os "seedlings" provenientes dos cruzamentos foram plantados, em 1972, no Centro Experimental de Campinas, sob espaçamento $3 \times 1 \mathrm{~m}$, constituindo lote de seleção da geração $F_{1}$. Esse lote recebeu, anualmente, os seguintes tratamentos culturais: desbrotas, podas de limpeza, ensacamento dos frutos, pulverizações fitossanitárias de inverno e de verão, adubações e cultivo do solo.

Como era de esperar, todos os "seedlings" dessa geração $F_{1}$ apresentaram frutos com pêlo, dada a recessividade do caráter película lisa da nectarina. As plantas que se destacavam celas melhores características vegetativas e produtivas, ou pela qualidade dos frutos, foram selecionadas para o prosseguimento do trabalho de melhoramento; nessas plantas, efetuaram-se, em junho-julho de 1974, autofecundaçōes controladas. Em outubro-novembro desse ano, fez-se a colheita dos frutos, extraindo-se as sementes resultantes das autofecundaçōes, separadamente por planta. Foram colhidas, nessa ocasião, também sementes oriundas de polinização livre das mesmas plantas, com o intuito de obter um maior número de "seedlings" na geração $F_{2}$.

Essas sementes deram origem a "seedlings" destinados à instalação, em 1975, de um novo lote de seleção, também no Centro Experimental de Campinas. Os tratamentos culturais proporcionados a! esse lote foram semelhantes aos já descritos para o da geração $F_{1}$.

A seleção preliminar de nectarinas, na geração $F_{2}$, fez-se basicamente em 1978. Efetuaram-se observações cuidadosas a partir da florada, anotando-se, por planta, os hábitos vegetativos e de frutificação, e. principalmente quanto ao tipo de película do fruto - lisa ou com pêlos. Os frutos colhidos em outubro-dezembro foram examinadics no laboratório, sob os seguintes aspectos, além do tipo de película: tamanho, formato, coloração externa e interna, peculiaridades da polpa, principalmente palatabilidade e aderência do caroço, registrando-se também a capacidade de resistência ao manejo.

Os dados coletados permitiram selecionar, de início, 24 plantas, que passaram a ser multiplicadas por enxertia, sobre pés francos de pessegueiro. Com as mudas enxertadas, instalaram-se, em fins de 1979 e início de 1980, campos experimentais, em várias regiōes do Estado, para serem conduzidos em forma de cultura. Desses campos, destacaram-se os localizados nas Estações Experimentais do Instituto Agronômico -.em Capão Bonito, Monte Alegre do Sul e Jundiaí - e nas propriedades dos fruticultores colaboradores - em Itupeva e Atibaia - que permitiram verificar, com acuidade, as potencialidades do material. 


\section{RESULTADOS E DISCUSSÃO}

Nos lotes experimentais, as seleçōes IAC N 4474-5 e IAC N 2374-8 confirmaram as boas características de produtividade e qualidade dos frutos, possibilitando que fossem lançadas como novos cultivares ao plantio comercial. Com os nomes de 'Precoce de Itupeva' e 'Branca de Guapiara', respectivamente, essas seleçōes vêm sendo fornecidas, a partir de 1982, em forma de borbulhas, aos fruticultores interessados no seu cultivo.

\subsection{Descrição dos novos cultivares}

'Precoce de Itupeva' (IAC N 4474-5) - Fruto de tamanho médio a grande, 90 a 100 gramas; forma globosa, ápice ausente, cavidade peduncular medianamente ampla e aprofundada; sutura pouco nítida, levemente saliente, dividindo o fruto em duas partes simétricas. Pele lisa, de coloração amarelo-creme-esverdeada, com tonalidade vermelha viva ocupando 40 a $50 \%$ da superfície; alguns frutos com pontuações suberificadas. Polpa branca, ligeiramente creme, de aspecto cristalino; textura macia e sucosa. Sabor doce-acidulado bem equilibrado e agradável, acentuadamente doce, lembrando o dos pêssegos mais apreciados em São Paulo; teor de açúcares ao redor de $15^{\circ}$ Brix e acidez $\mathrm{pH} 4,5$. Caroço de tamanho médio a pequeno, arredondado, solto a meio solto, sem auréola ao seu redor.

Planta de vigor médio, ramos frutíferos um tanto ralos, mas bem desenvolvidos, lembrando o hábito da nectarina 'Colombina' (Fla 19-37 S). Alta produtividade: médias de $16,3 \mathrm{~kg}$ e $31,0 \mathrm{~kg}$, por planta de dois e três anos de idade respectivamente, no ensaio levado a efeito na Estação Experimental de Capão Bonito. Maturação precoce: meados de outubro a inicio de novembro, logo em seguida à do 'Rubro-sol' e 'Colombina'. $\mathrm{Na}$ seleção preliminar, foi designada como IAC N 4474-5, significando a quinta planta originária da combinação $n^{\prime \prime} 44$ - polinização aberta do pêssego IAC 2370 , levada a efeito em 1974. O pêssego IAC 2370, por sua vez, é híbrido $F_{1}$ resultante do cruzamento 'Cristal' x 'Colombina' efetuado em 1970. O nome 'Precoce de Itupeva' foi conferido pelo fato de os produtores do municipio de Itupeva (SP), terem sido os primeircs a demonstrar interesse no seu cultivo, com base nas observações dos resultados locais ${ }^{(4)}$.

Branca de Guapiara (IAC N 23\%4-8) - Fruto de tamanho médio a grande, 100 gramas; forma globosa, ligeiramente alongacia; ápice quase ausente; cavidade peduncular de largura mediana e pouco profunda; sutura pouco nítida, dividindo o fruto em duas partes simétricas. Pele bem lisa, de coloração amarelo-creme esverdeada, com leve matiz róseo-avermelhado. Polpa branca, de boa textura e medianamente sucosa;

(4) Propriedade do Sr. Adão Kobayashi, a quem os autores agradecem a colaboração. 
auréola tênue no caroço, que é de tamanho médio e solto. Sabor doce-acidulado suave, bem equilibrado e agradável; teor de açúcares ao redor de $14^{\circ}$ Brix e acidez $\mathrm{pH} 4,2$.

Planta vigorosa, com excelente enfolhamento e abundância em ramos frutíferos. Alta produtividade: no ensaio de Capão Bonito, constatou-se produção de $19,4 \mathrm{~kg}$ por planta de dois anos, e de $35,8 \mathrm{~kg}$ pela de três anos. Maturação mediana: fins de novembro a meados de dezembro. Foi selecionada sob a designação de IAC N 2374-8, ou seja, oitava planta originária da combinação $\mathrm{n}^{\circ} 23$ - autofecundação do pêssego IAC 2670, levada a efeito em 1974. O pêssego IAC 2670, por sua vez, é híbrido $\mathrm{F}_{1}$ resultante do cruzamento 'Supermel' $\mathrm{x}$ 'Colombina', efetuado em 1970. Conferiu-se o nome 'Branca de Guapiara' em homenagem a Guapiara (SP), um dos principais municipios paulistas produtores de pêssegos e nectarinas e cujas condiçōes climáticas, de inverno relativamente frio, sugerem melhor comportamento do cultivar de maturação mediana.

\subsection{Perspectivas dos novos cultivares}

Como foi visto, a exploração da nectarina nas principais regiões persícolas do Estado de São Paulo baseia-se, hoje apenas em dois cultivares - 'Rubro-sol' e 'Colombina' - que são de maturação bastante precoce, e concentram a sua safra num curto período, no início de outubro. São nectarinas de aspecto bem atraente, porém apresentam acidez pronunciada, que não satisfaz ao paladar do consumidor mais exigente, acostumado a frutas mais doces.

Nessas condições, os cultivares ora apresentados - 'Precoce de Itupeva' (IAC N 4474-5) e 'Branca de Guapiara' (IAC N 2374-8) constituem novas opçōes ao cultivo de nectarina nas regiões de inverno brando. Pelas respectivas épocas de maturação, que ocorrem posteriormente às de 'Rubro-sol' e 'Colombina', propiciam a ampliacão do periodo de safra e, conseqüentemente, melhor distribuição de trabalho e comercialização ao fruticultor. Os frutos, de polpa branca e externamente menos vistosos que as atuais nectarinas existentes no mercado, poderāo, a princípio, causar estranheza ao consumidor. Este, no eritanto, deverá apreciar o sabor dessas novas nectarinas, acentuadamente doces, que lembra o dos pêssegos mais procurados em São Paulo.

\section{SUMMARY}

\section{'PRECOCE DE ITUPEVA' AND 'BRANCA DE GUAPIARA':} TWO NEW WHITE FLESH NECTARINES

'Precoce de Itupeva' (IAC N 4474-5) and 'Branca de Guapiara' (IAC N 2374-8) are the two new low chilling nectarine selections adapted to the mild winter conditions prevailing in the State of São Paulo. They are the result of the nectarine breeding work started at the Instituto Agronômico, Campinas, Statc of São Paulo, Brazil, in 1970, with crosses between some local peach cultivars and nectarine selections introduced from Florida, USA. 'Precoce de Itupeva' parentage is 'Cristal' 
$\mathbf{x}$ 'Colombina', $F^{2}$ open pollinated, with 'Branca de Guapiara' is 'Supermel' $\mathrm{x}$ 'Colombina', $\mathrm{F}^{2}$ self-pollinated. Both are white flesh, freestone nectarines, of excellent quality and sweet taste.

\section{REFERENCLAS BIBLIOGRAFICAS}

1. CAMPINAS. Instituto Agronômico. Cultivares lançados pelo IAC no periodo 1968-1979. O Agronômico, Campinas, 32:39-168, 1980.

2. OJIMA, M.; CAMPO DALL'ORTO, F. A.; RIGITANO, O.; TOMBOLATO, A. F. C.; BARbosA, W. Melhoramento da nectarina (Prunus persica, var. nucipersica) em São Paulo. I. Cruzamentos de 1970: seleção nas gerações $F^{1}$ e F². Bragantia, Campinas, 42:1-14, 1983.

3. RigitaNo, O.; OJIMA, M.; CAMPO DALlorTO, F. A. Comportamento de novas seleções de pêssegos introduzidos da Flórida. Campinas, Instituto Agronômico, 1975. 12p. (Circular, 46)

4. SHARPE, R. H. Sunred - a nectarine for Central Florida. Gainesville, University of Florida, 1964. 4p. (Circular S-158)

5. —— AITKEN, J. B. Progress of the nectarine. Proceedings of the Florida State Horticultural Society, Miami, 84:338-345, 1971. 